\title{
Wind-Induced Torsional Loads on Low Buildings
}

\author{
M. Elsharawy, T. Stathopoulos and K. Galal \\ Department of Building, Civil, and Environmental Engineering, Concordia University, 1455 De Maisonneuve \\ West, Montreal, Quebec, Canada, H3G $1 M 8$
}

\begin{abstract}
Wind-induced instantaneous pressures on low building envelopes continuously vary in temporal and spatial dimensions and this may lead to significant torsional moments on the building's lateral load resisting system. Studies on wind-induced torsional loads on low buildings are very limited. Wind-induced torsion provisions in the American Society of Civil Engineers Standard (ASCE 7-10), the National Building Code of Canada (NBCC 2010), and the European Code (EN 1991-1-4) were reviewed and compared for three gabled-roof $\left(18.4^{\circ}\right)$ low buildings. Significant discrepancies were found among the provisions of these wind standards in evaluating torsional wind loads on low buildings. In addition, wind-induced torsional loads on low buildings have been measured in a boundary layer wind tunnel. Three low buildings, with the same plan dimensions but different gabled-roof angles $\left(0^{\circ}, 18.4^{\circ}, 45^{\circ}\right)$ and two different heights (i.e. full, and half eave building height) were tested in simulated open and urban terrain exposures for different wind directions (from $0^{\circ}$ to $180^{\circ}$ every $15^{\circ}$ ). The experimental results were compared with current wind-induced torsional load provisions. It was found that NBCC 2010 underestimates the torsional moments on low buildings significantly.
\end{abstract}

\section{Keywords}

Wind-induced torsion, wind loads, low buildings, wind tunnel experiments, wind codes and standards 


\section{INTRODUCTION}

Wind-induced loads on low building envelopes continuously vary in temporal and spatial dimensions. The variation of local wind pressures on building cladding and the total effective wind loads (base shears/overturning moments) on the main structural building systems have been investigated extensively in the past few decades. However, only a small number of studies examined wind-induced torsional loads on main resisting structural building systems as shown clearly in the comprehensive reviews by Holmes, 1983, Stathopoulos, 1984 and Krishna, 1995. Such loads are mainly generated as a result of non-uniform horizontal distribution of wind forces on the main resisting system. The simplified methods introduced in the current wind standards and codes of practices to predict the actual wind load effects on buildings have not been examined to ensure that these provisions are adequate for predicting wind-induced torsion on buildings. Overlooking the accurate representation of wind-induced torsional loads on buildings due to the limited knowledge in this area, may lead to unrealistic wind design loads, which may be conservative in certain design situations and detrimental in others. Accordingly, accurate evaluation of wind-induced torsional loads has a significant effect on the serviceability and survivability of building design.

The majority of residential and commercial buildings worldwide are categorized as low buildings. Moreover, low buildings are prone to excessive damages in wind disaster events. An example for an actual low building damage possibly caused by torsion is presented in Figure 1 (taken from American Association of Wind Engineering web site (http://www.aawe.org/gallery/?p=3\&c=)). As illustrated, the non-uniform wind load distribution, which is the main source for generating torsion, may be the reason for damage. On the other hand, the development of provisions for the evaluation of wind loads on low buildings was based on the research carried out at the University of Western Ontario (UWO) in the late 70 's, when an extensive experimental program in a boundary layer wind tunnel 
considered a variety of rectangular low buildings with different dimensions, roof slopes and upstream terrain exposures (Davenport et al, 1977, 1978). However, wind-induced torsional loads were not examined in detail. In contrast, wind-induced torsion has been measured in the wind tunnel for three low-rise buildings with different aspect ratios in open terrain exposure by Isyumov and Case, 2000. This unique study suggested that applying partial wind loads, similar to those implemented for the design of tall buildings, would improve the design of low-risebuildings until more pertinent data become available.

The main purpose of the study reported in this paper is, in the first instance, the assessment of wind-induced torsional loads on low buildings in three national building codes and standards; namely the American Society of Civil Engineers Standard (ASCE 7-10), the National Building Code of Canada (NBCC 2010), and the European Code (EN 1991-1-4). Three low buildings with different horizontal aspect ratios (length/width) varying from 1 to 3 in open terrain exposure were analyzed using the three standards. The comparisons have demonstrated that North American and European Codes and Standards have quite different provisions for wind-induced torsion acting on low buildings. This established the need to examine experimentally wind-induced torsional loads on low buildings. In this phase three gabled-roof low buildings with the same plan dimensions but different angles $\left(0^{\circ}, 18.4^{\circ}, 45^{\circ}\right)$ were tested in the Building Aerodynamics Laboratory located in the Engineering Complex at Concordia University, Montreal, Canada. The selection of the three building configurations followed the geometries of the original UWO study leading to the current code provisions for wind loading on low buildings. The three buildings were tested in simulated open and urban terrain exposures for several wind directions. The experimental results, in terms of shear force and torsional moment coefficients, were also compared to the provisions of the abovementioned building codes and standards. 


\section{WIND-INDUCED TORSION IN WIND CODES AND STANDARDS}

Contemporary building codes and standards introduce various analytical load patterns to evaluate the actual wind load effects on buildings. For wind-induced torsional loads on buildings, inadequate information and sometimes unclear or ambiguous statements are found in these descriptive code models, as it will be indicated in the following sections. Ongoing updates and sufficient assessment are always considered critical towards reliable analytical approaches aiming at better evaluation of actual wind effects on buildings. In this section the wind-induced torsional load provisions in ASCE 7-10, NBCC 2010, and EN 1991-1-4 will be presented, discussed and compared with available experimental data from past and current studies.

\subsection{Overview of the wind-induced torsion provisions in ASCE 7-10, NBCC 2010, and EN 1991-1-4}

Wind-induced loads on buildings vary instantaneously in temporal and spatial dimensions. Buildings may experience a significant torsional moment due to the shift between the resultant of aeroelastic wind forces and the building center of rigidity. This torsional moment should be accounted for during the building design process. Unfortunately, due to the limited available sources, most of the building codes provide inadequate information about windinduced torsion on buildings. As a step towards better estimation of wind-induced torsional loads on low buildings - defined generally as having heights less than $20 \mathrm{~m}$, an assessment of the wind-induced torsional load provisions is necessary.

Two main approaches are being used in the wind loading standards for the evaluation of the actual effects of wind-induced torsional loads on buildings. The first approach is implemented by applying reduced uniform wind loads on building surfaces with additional equivalent eccentricity from the building dimensions (used in ASCE 7-10), while the other way is by 
applying non-uniform wind loads (used in NBCC 2010 and EN 1991-1-4). The non-uniform wind loads can be simulated by either increasing the wind pressure on building corners, by using partial wind load acting on one part of a building face, or by applying a triangular wind load on building surfaces. The following sections discuss the different approaches used to calculate the wind-induced torsional loads in the American, the Canadian and the European wind codes/standards:

\subsubsection{American Society of Civil Engineers (ASCE 7-10)}

Wind load provisions in ASCE 7-10 include two analytical methods to estimate wind forces on the main wind force resisting system (MWFRS): the simplified (envelope) method, which is applicable to low buildings - defined as buildings with mean roof height $(\mathrm{h})<18 \mathrm{~m}$ and $(\mathrm{h} / \mathrm{w}<1)$ where $\mathrm{w}$ is the least horizontal dimension - and the detailed (directional) method, which can be used for designing buildings of all heights. The simplified method has three main load cases; namely transverse (perpendicular to ridge) load case, longitudinal (parallel to ridge) load case, and torsional load case. The description of the three load cases is given in ASCE 7-10 in chapter 28, Figure 28.4-1. In the third case, the torsional effects have been taken into account by applying only $25 \%$ of the full design wind pressure on half of the building faces. Exceptionally, one-story buildings with $\mathrm{h}<9.1 \mathrm{~m}$ and two-story buildings framed with light frame construction or designed with flexible diaphragms need not be designed for torsional loads. On the other hand, the detailed/directional method has four load cases described in ASCE 7-10, chapter 27, Figure 27.4-8. In the first and third cases, uniform wind loads are applied without any torsional loads. Torsional wind loads are specified in cases 2 and 4 by introducing two non-dimensional parameters, $15 \%$ equivalent eccentricity of the building dimension and 0.75 and 0.563 reduction factors respectively for the equivalent static 
wind pressure. Specific exemptions are provided in Appendix D of the Commentary of ASCE 7-10, which also says:

"Although this is more in line with wind tunnel experience on square and rectangular buildings with aspect ratios up to about 2.5, it may not cover all cases, even for symmetric and common building shapes where larger torsions have been observed" (C27.4.6)

\subsubsection{National Building Code of Canada (NBCC 2010)}

Among the national building codes and standards, the NBCC was the first to include in its provisions the effects of wind-induced torsional loads on buildings. In fact, there are two analytical methods stated in NBCC 2010 to predict wind-induced torsional moments on buildings. The simplified (static) method is appropriate for low buildings ( $\mathrm{h}<20 \mathrm{~m}$ and $\mathrm{h} / \mathrm{w}<$ 1) and medium height buildings (generally 20 - $60 \mathrm{~m}$ high), while the detailed (dynamic) method is specified for high-rise buildings (height $>60 \mathrm{~m}$ ). For low buildings, two wind direction ranges are considered in the simplified method, i.e. the transverse (perpendicular to ridge) and the longitudinal (parallel to ridge). In this method, the external peak (gust) pressure coefficients $\left(\mathrm{C}_{\mathrm{p}} \mathrm{C}_{\mathrm{g}}\right)$ provided for low rise buildings implicitly account for torsional loads (Commentary I, figure I-7). The wind-induced torsion is introduced by increasing the wind pressure on the corner/end zone. Based on the concept of partial loads acting on building envelope, the static method for medium height buildings and the dynamic method have four load cases (Commentary I, figure I-16). In Cases A and C, symmetric uniform loads are considered, in order to estimate the maximum base shears and overturning moments. On the other hand, partial wind loads are recommended to create equivalent torsional building loads 
in Cases B and D. Nevertheless, the choice of partial loads could be difficult for design engineers as can be seen from the code statements quoted below:

"In case B, the full wind pressure should be applied only to parts of the wall faces so that the wind-induced torsion is maximized" (note (2) to figure I-16); and

“... the influence of removing 50\% of the case C loads from parts of the face areas that maximizes torsion, as shown in figure I-16, case D, should be investigated" (Commentary I, 37).

\subsubsection{EN 1991-1-4 : Actions on structures - General actions - Part 1-4: wind actions}

The Eurocode defines one unified analytical method that can be used for predicting the wind forces on all building types regardless of height. Wind pressure and force coefficients are described in Eurocode part 4 section 7. Torsional effects are taken into account by applying non-uniform pressures and forces, as shown in EN 1991-1-4, Figure 7.1. A triangular wind load is applied on the windward surface with a rectangular load on the leeward face of the building. Limited information regarding wind-induced torsional loads only for rectangular buildings can be found in this code. In addition, EN 1991-1-4 includes a rather difficult to apply statement regarding the torsional wind load case:

"For other cases an allowance for asymmetry of loading should be made by completely removing the design wind action from those parts of the structure where its action will produce a beneficial effect". (Section 7.1.2 - note (b))

In summary, a review of the current approaches stated in ASCE 7-10, NBCC 2010, and EN 1991-1-4 for predicting torsional wind loads on low buildings is presented in Figure 2. In ASCE 7-10, the wind pressure is increased on areas close to building corners (end zone). 
Moreover, a $75 \%$ reduction of the wind loads on half of the building faces is required. In NBCC 2010, only increasing the wind pressure on the end zone is required while a triangular wind load is implemented in EN 1991-1-4. In general, these procedures lack the full details for describing the torsional wind load cases. As clearly seen in some code statements for partial wind load cases the decision has to be made by designer to specify from where the wind loads should be removed in order to maximize torsion. Yet, these are simple and typical building configurations (i.e. buildings with symmetrical rectangular or square plan) and there is no guidance for designing buildings with different plan sections, say L- or T-shapes, for which the torsional moments are expected to be more critical.

\subsection{Comparisons of torsion provisions using current codes and standards}

In this section, comparisons among ASCE 7-10, NBCC 2010, and EN 1991-1-4 provisions for wind-induced torsional loads on low buildings are presented. Different building configurations are analyzed using the three codes/standards selected. In particular, three low buildings - gabled roof angle $18.4^{\circ}$ width $(B=16 \mathrm{~m})$, and eave height $(\mathrm{H}=6 \mathrm{~m})$ with different aspect ratios $(\mathrm{L} / \mathrm{B}=1,2$, and 3$)$ in an open terrain have been examined. The simplified methods assigned for low buildings have been applied. Also, it is of interest to apply the detailed methods provided for medium height buildings, as the structural behaviour of these buildings is quasi-similar with that of low buildings. The detailed method, directional approach in ASCE 7-10 assigned for all building heights and static in NBCC 2010 assigned for medium height buildings, have been applied, in addition to the analytical method available in EN 1991-1-4. The assessment of the torsional load cases in the code provisions has been carried out by estimating both the maximum torsional moment and the corresponding shear force. On the other hand, the wind velocity was adjusted by using the so-called Durst curve also provided in the ASCE 7-10 Commentary, Figure C26.5.1. This curve describes the 
relation between the wind speed averaged over $\mathrm{t}$ seconds, and the mean hourly wind speed at reference height $(10 \mathrm{~m})$. This is used in order to alleviate the effect of using the 3 -sec reference wind speed in ASCE 7-10, as opposed to the mean hourly and 10-minute wind speed in NBCC 2010 and EN 1991-1-4, respectively. The results were presented in terms of shear coefficient and equivalent eccentricity estimated in transverse direction as per the following equations:

$\mathrm{C}_{\mathrm{V}}=\frac{\text { Base shear force }}{0.5 \rho \mathrm{V}_{\mathrm{H}}^{2} \mathrm{BH}}$

where $\rho=$ air density $\left(\mathrm{kg} / \mathrm{m}^{3}\right)$; and $\mathrm{V}_{\mathrm{H}}=$ mean wind velocity at eave height $(\mathrm{m} / \mathrm{s})$.

$\mathrm{e}(\%)=\frac{\text { Base torsional moment }}{\mathrm{L} * \text { Base shear force }}$

It is also important to compare the magnitude of the torsional moment estimated for the three low buildings based on the application of the wind load patterns introduced (simplified and detailed methods) in the standards considered with the past wind tunnel results. The estimated torsional moment is normalized to get the torsional coefficient according to:

$\mathrm{C}_{\mathrm{T}}=\frac{\text { Base torsional moment }}{0.5 \rho \mathrm{V}_{\mathrm{H}}^{2} \mathrm{~B} \mathrm{~L} \mathrm{H}}$

\subsubsection{Results}

Comparisons among ASCE 7-10, NBCC 2010, and EN 1991-1-4 for three low building geometries are presented. Figure 3 shows the results for torsional loads case, maximum torsional moment and the corresponding shear. These values are estimated by applying the simplified methods; the envelope and static methods assigned for low buildings in ASCE 7- 
10 and NBCC 2010 respectively, in addition to the analytical method in EN 1991-1-4. As clearly shown, significant differences are found among the three national codes/standards in evaluating the torsional moment, whereas smaller differences are found in evaluating corresponding shear forces. The distribution of wind loads introduced in this load case (maximum torsion and the corresponding shear force) is also very different in these codes. ASCE 7-10 introduces equivalent eccentricity about $17 \%$ of the building length while the NBCC 2010 and EN 1991-1-4 have eccentricities about 4\%, and 8\% of the building length, as Figure 3 clearly shows. The results show that ASCE 7-10 torsional moment estimated for buildings with aspect ratios 2 and 3 are three times higher than those of NBCC 2010, and more than twice the torsional moments calculated by EN 1991-1-4 for buildings with aspect ratios 1 and 2. Clearly, NBCC 2010 provides significantly lower values for the torsional moment on the three low buildings compared to ASCE 7-10 and EN 1991-1-4. In Figure 4, comparisons among the three codes/standards using the detailed methods (directional method in ASCE 2010, static method for medium height buildings and the analytical method in EN 1991-1-4) for the same buildings are presented. Although significant differences of equivalent eccentricities have been found among the codes/standards, different values of the corresponding shear forces compensate and produce more comparable torsional moments with the exception of the Eurocode values being on the low side. For example, NBCC 2010 introduces the highest equivalent eccentricity value, which is equal to $25 \%$ of the building length but it also has the smallest value for the corresponding shear force. Thus, it appears the detailed method fixes an appropriate equivalent eccentricity depending on the value of shear coefficient in order to produce comparable torsional moments for all cases. Although the torsional load cases required by the detailed methods in ASCE 7-10 and NBCC 2010 provide comparable torsional moments, the latter were generated by applying different wind loads with different eccentricities/distributions. Indeed, ASCE 7-10 requires applying 75\% of the 
full wind loads (maximum shear force), while NBCC 2010 requires applying 50\% of the total wind loads (see Figure 5). On the other hand, the torsional coefficients evaluated by EN 1991-1-4 for the same buildings are $0.10,0.24$, and 0.50 , i.e. almost half of the torsional coefficients proposed by the ASCE 7-10 and NBCC 2010. This may be attributed to the very small equivalent eccentricity proposed by the EN 1991-1-4 which is about 7\% of the building length compared to ASCE 7-10 (15\%) and NBCC 2010 (25\%).

Figure 6 presents peak torsional moment coefficients estimated by the simplified and the detailed methods in the three codes/standards with the peak torsional coefficient measured in past wind tunnel tests. Indeed the detailed method proposed in ASCE 7-10 and NBCC 2010 succeeds to predict the wind-induced torsional moment on low buildings, particularly for small aspect ratios. However, significant differences have been found between the simplified methods of ASCE 7-10 and NBCC 2010 when compared with the wind tunnel test results. The simplified methods in both standards underestimate the torsional moment due to wind on low buildings. However, the simplified method (ASCE 7-10) appears closer to the wind tunnel results. EN 1991-1-4 underestimates the torsional moment due to wind on low buildings by almost $50 \%$.

As previously mentioned, the study conducted by Isyumov and Case, 2000 was the only study that measured torsional moments on low buildings. Clearly, more pertinent experimental data are necessary for better estimation of wind-induced torsional loads on low buildings.

\section{WIND TUNNEL STUDIES}

\subsection{Building models}


The experiments were carried out in the boundary layer wind tunnel (working section $1.8 \mathrm{~m}$ wide, approximately $1.8 \mathrm{~m}$ high and $12.2 \mathrm{~m}$ long) at the Building Aerodynamics Laboratory, Concordia University. Three low building models, with the same plan dimensions but different gabled-roof angles $\left(0^{\circ}, 18.4^{\circ}, 45^{\circ}\right)$, were tested in the boundary layer wind tunnel. The building models, with external dimensions of $152.5 \mathrm{~mm}$ (length) by $97.5 \mathrm{~mm}$ (width) and $30 \mathrm{~mm}$ (eave height, "H"), were constructed at 1:400 geometric scale to represent actual buildings with $61 \mathrm{~m}$ length, $39 \mathrm{~m}$ width, and $12 \mathrm{~m}$ eave height. Building A, Building B and Building $\mathrm{C}$ are shown in Figure 7 equipped with 76, 126 and 126 pressure taps, respectively. Building A has all pressure taps on the side walls since the uplift pressure on the top surface will not contribute to the base shear forces or to the torsional moment about the vertical building axis. All building models were tested in simulated open-country and urban terrain exposures, at two building heights as shown in Figure 7. D (actual full eave height $(\mathrm{H})=12$ $\mathrm{m}$, and half eave height $(\mathrm{H} / 2)=6 \mathrm{~m}$ ), for a half wind direction cycle (from $0^{\circ}$ to $180^{\circ}$ every $\left.15^{\circ}\right)$

\subsection{Atmospheric boundary layer (wind / terrain) simulation}

An open-country and urban terrain exposure were simulated in the wind tunnel. Figure 8 shows the flow approach profiles of the mean wind velocities and the turbulence intensities measured using a 4-hole Cobra probe (TFI) for the two terrain exposures. The gradient wind velocity for open country exposure is $13.6 \mathrm{~m} / \mathrm{s}$ at a height of $\mathrm{zg}_{\mathrm{g}}=70 \mathrm{~cm}$ and for urban terrain exposure is $14.1 \mathrm{~m} / \mathrm{s}$ at a height of $\mathrm{zg}=90 \mathrm{~cm}$. The power law exponents for the wind velocity profiles simulated in these tests were 0.16 and 0.30 for the open-country and the urban terrain exposure respectively. The pressure measurements on the models were conducted using a system of miniature pressure scanners from Scanivalve (ZOC33/64Px) and the digital service 
module DSM 3400. All measurements were synchronized with a sampling rate of $312.5 \mathrm{~Hz}$ on each channel for a period of $27 \mathrm{sec}(120 \mathrm{~min}$ in full scale).

\subsection{Evaluation procedure}

Figure 9 shows a schematic representation of external pressure distributions on building envelope at a certain instant, the exerted shear forces and torsional moment. Pressure measurements are scanned simultaneously. The instantaneous wind force at each pressure tap is calculated according to

$$
\mathrm{f}_{\mathrm{i}, \mathrm{t}}=\left(\mathrm{p}_{\mathrm{i}, \mathrm{t}} \times \mathrm{A}_{\text {effective }}\right) \quad \mathrm{f}_{\mathrm{j}, \mathrm{t}}=\left(\mathrm{p}_{\mathrm{j}, \mathrm{t}} \times \mathrm{A}_{\text {effective }}\right)
$$

where $\mathrm{P}_{\mathrm{i}, \mathrm{t}}$, and $\mathrm{P}_{\mathrm{j}, \mathrm{t}}$ are instantaneous pressures measured at each pressure tap.

The wind forces exerted at pressure tap locations in $\mathrm{X}$-and $\mathrm{Y}$-directions are noted by $\mathrm{f}_{\mathrm{i}, \mathrm{t}}$ and $\mathrm{f}_{\mathrm{j}, \mathrm{t}}$, respectively. For each wind direction; the horizontal force components in $\mathrm{X}$-and $\mathrm{Y}$ directions, and the total shear force, are evaluated according to

$$
F_{X}=\sum_{i=1}^{N} f_{i, t} \quad F_{Y}=\sum_{j=1}^{M} f_{j, t} \quad F=\sqrt{F_{X}^{2}+F_{Y}^{2}}
$$

where $\mathrm{N}$ and $\mathrm{M}$ are the numbers of the pressure taps on the longitudinal and transverse directions, respectively

All these forces are normalized with respect to the dynamic wind pressure at the mean roof height as follows:

$$
\mathrm{C}_{\mathrm{vx}}=\frac{\mathrm{F}_{\mathrm{X}}}{0.5 \rho \mathrm{V}_{\mathrm{h}}^{2} \mathrm{Bh}} \quad \mathrm{C}_{\mathrm{vy}}=\frac{\mathrm{F}_{\mathrm{y}}}{0.5 \rho \mathrm{V}_{\mathrm{h}}^{2} \mathrm{Bh}} \quad \mathrm{C}_{\mathrm{vt}}=\frac{\mathrm{F}}{0.5 \rho \mathrm{V}_{\mathrm{h}}^{2} \mathrm{Bh}}
$$


where $\rho=$ air density $\left(\mathrm{kg} / \mathrm{m}^{3}\right) ; \mathrm{V}_{\mathrm{h}}=$ mean wind velocity at mean roof height $(\mathrm{m} / \mathrm{s}) ; \mathrm{B}=$ building width $(\mathrm{m})$, and $\mathrm{h}=$ mean roof building height $(\mathrm{m})$

The torsional coefficients are evaluated based on:

$\mathrm{C}_{\mathrm{T}}=\frac{\mathrm{M}_{\mathrm{T}}}{0.5 \rho \mathrm{V}_{\mathrm{h}}^{2} \mathrm{BLh}}$

where $\mathrm{L}=$ building length

\section{WIND TUNNEL MEASUREMENT RESULTS}

\subsection{Base shear and torsional coefficient}

Figure 10 shows the variation of peak shear coefficients (i.e. in X-, Y-direction, and total shear), with wind direction for the three building models tested in simulated open-country exposure. For buildings A and B, the shear coefficients have almost similar values for most of the tested wind directions, while building $\mathrm{C}$ has higher shear coefficient values. The maximum shear forces in $\mathrm{x}$-direction occur for wind directions from $0^{\circ}$ to $45^{\circ}$; while in $\mathrm{y}$ direction when wind is almost perpendicular to building face, i.e. $90^{\circ}$. It is also important to mention that increasing the number of pressure taps used in y-direction to measure the pressure distributions will help to get more details about the variation of shear force in this direction. Although, the determination of the shear coefficient is important to propose equivalent wind loading, identification of horizontal distribution of these wind loads on building structural system still requires information about the torsional moment. The variation of the peak torsional coefficient with wind direction is presented in Figure 11 for all three buildings in open-country and urban terrain exposures. The maximum torsional moments occur for wind directions from $15^{\circ}$ to $45^{\circ}$ for all buildings. As a result of the building models having symmetric shapes, the evaluated mean torsions are zero for wind directions 
perpendicular to building faces, i.e. $0^{\circ}$ and $90^{\circ}$. However, there are significant maximum and minimum torsional coefficients for these wind directions due to the lack of wind pressure correlation over the building envelope in the horizontal direction.

\subsection{Effect of roof slope}

The shear and torsional coefficients for the building models have not been affected much by changing the roof slope from $0^{\circ}$ to $18.4^{\circ}$ for most wind directions, as shown in Figures 10 and 11. However, significant difference for shear coefficient has been noticed when roof angle was changed to $45^{\circ}$. Table 1 presents the most critical values of shear coefficients evaluated in open and urban terrain exposures for all three buildings tested at full and half eave heights, while Table 2 presents the most critical values of torsional coefficients. Increasing the roof slope leads to an increase of shear forces and torsional moments. At the same time, mean wind velocity and mean roof height are increased. In open terrain exposure, changing the roof angle from $0^{\circ}$ to $45^{\circ}$ for buildings tested at full eave height results in an increase of the shear coefficient by about $40 \%$ and the torsional coefficient by about $20 \%$.

\subsection{Effect of building height}

Building models $\mathrm{A}, \mathrm{B}$ and $\mathrm{C}$, with $0^{\circ}, 18.4^{\circ}$ and $45^{\circ}$ roof angles respectively, were tested in open and urban terrain exposures at full $(\mathrm{H})$ and half $(\mathrm{H} / 2)$ building eave height. The peak shear force and torsional moment-coefficients were evaluated for each wind direction (see Tables 1 and 2). Although reducing the height to half results in decreasing the shear and torsional moment, the shear and the torsional coefficients are not affected significantly due to the change of the dynamic wind velocity and the mean roof height as well. Clearly, the reduction in shear forces for the full height low buildings and those with half height is similar for torsional moments in open and urban terrain exposures. For instance, the ratios between 
the shear forces evaluated for full- and half-height buildings $\mathrm{A}, \mathrm{B}$, and $\mathrm{C}$ in open terrain exposure were $2.80,1.80$ and 1.35 , respectively; the same ratios for the torsional moments were $2.80,1.95$ and 1.40 .

\subsection{Effect of terrain exposure}

The mean wind velocity at the mean roof height has been decreased by about $35 \%$ in urban than open terrain exposure. This is associated with increasing the turbulence intensity in urban terrain by about $33.5 \%$ in comparison with open terrain exposure. Thus, the shear and torsion measured in open terrain are higher than those in urban terrain. For instance, the ratios between the shear forces measured in open terrain to those measured in urban terrain exposure for buildings $\mathrm{A}, \mathrm{B}$, and $\mathrm{C}$ are $1.15,1.23$ and 1.10 respectively, for full building height while these ratios for torsional moments are 1.10, 1.23 and 1.12. On the other hand, the shear and torsional coefficients for the low-rise building models tested in urban terrain exposure are higher (about double) than those in open terrain exposure (see Tables 1 and 2).

\section{COMPARISON OF WIND TUNNEL RESULTS WITH CODE AND STANDARD PROVISIONS}

The results of the wind tunnel tests for buildings $\mathrm{A}, \mathrm{B}$ and $\mathrm{C}$ are compared to the values for base shear force and torsional moment evaluated by the three aforementioned building codes and standards, ASCE 7-10, NBCC 2010 and EN 1991-1-4. The experimental results are compared with the provisions of the simplified (envelope/static) method and the analytical (detailed) method in the EN 1991-1-4 building codes. For the simplified method calculations in ASCE 7-10, figure 28.4-1 is used to get the external pressure coefficients (GCpf). The basic (transverse) and torsional load cases presented in figure 28.4-1 of ASCE 7-10 are used 
to estimate the maximum torsional moment and base shear for the buildings. The static method calculations in NBCC 2010 for the torsional and shear coefficients were derived based on figure I-7 of NBCC 2010, where the external peak (gust) pressure coefficients $\left(\mathrm{C}_{\mathrm{p}} \mathrm{C}_{\mathrm{g}}\right)$ are provided for low buildings. ASCE 7-10 and NBCC 2010 calculations were carried out considering the open terrain exposure C, and terrain category II, respectively. Likewise for EN 1991-1-4, external pressure coefficients for vertical walls of rectangular plan buildings are calculated using Figure 7.5 and Table 7.1 available in section 7, while for the external pressure of duo-pitch roofs, values are provided in the same section (Figure 7.8 and Table 7.4a). It is also important to mention that shear forces and torsional moments were adjusted in a way to eliminate the directional reduction factors adopted by the three building codes and standards. The directional factor was taken as 1 for ASCE 7-10 and EN 1991-1-4, while for NBCC 2010 the calculated values were increased by $25 \%$ since the directional factor is implicit as 0.8 .

Furthermore, for validation purposes, it is important to compare the current wind tunnel results with data available from past studies. As already mentioned, Isyumov and Case, 2000 is the only study addressing wind-induced torsional loads on low buildings. It will be only possible to compare results evaluated for testing Building B, since all building models tested by that study have gabled roofs with $18.4^{\circ}$ angle.

The results of the wind tunnel tests and the proposed values by these standards are normalized by using Eqs. 6 and 7 to get shear and torsional coefficients. Figure 12 summarizes the peak shear and torsional coefficients evaluated; either by the wind tunnel study, or by the provisions of standards considered. The maximum torsional coefficient for building B (aspect ratio=1.6, scaled 1:400) evaluated by the current wind tunnel study is 0.27 . The study conducted by Isyumov and Case, 2000 for a similar building (aspect ratio $=2$, scaled $1: 100$ ) is 0.25 . Clearly, the three building codes and standards succeed to predict the 
maximum shear forces. However, EN 1991-1-4 is over-estimating the shear force on the tested buildings. On the other hand, ASCE 7-10 provides comparable torsional moments with the wind tunnel results. However, NBCC 2010 and EN 1991-1-4 underestimate the torsional moment on low buildings, in some cases significantly.

\section{CONCLUSIONS}

This paper examines wind-induced torsional loads on low-rise buildings. A set of wind tunnel test results have been presented and compared with the provisions for torsion on low buildings in the Canadian, American and European wind standards. The experimental results show the significant effect of building geometry and the terrain exposure on the generated shear forces and torsional moments. ASCE 7-10 provisions compare well with the experimental results for shear forces and torsional moments. The Canadian and European codes underestimate wind-induced torsion on low buildings. Additional data would be desirable for a reliable assessment of wind-induced torsion on low buildings.

\section{ACKNOWLEDGMENTS}

The authors are grateful for the financial support received for this study from the Natural Sciences and Engineering Research Council of Canada.

\section{REFERENCES}

ASCE/SEI 7-10, 2010. Minimum design loads for buildings and other structures. Published by the Structural Engineering Institute of ASCE, Reston, VA 
Davenport, A.G., Surry, D. and Stathopoulos, T., 1977. Wind loading on low-rise buildings: final report on phases I and II, University of Western Ontario, Eng. Sci. Res. Rep., BLWTSS8.

Davenport, A.G., Surry, D. and Stathopoulos, T., 1978. Wind loading on low-rise buildings: final report on phase III, University of Western Ontario, Eng. Sci. Res. Rep., BLWT-SS4.

Holmes, J. D., 1983. Wind Loads on Low Rise Buildings - A Review. CSIRO Div. of Building Research, Highett. Victoria, Australia

Isyumov and Case, P. C., 2000. Wind-Induced torsional loads and responses of buildings, in: Proceedings of the 2000 Structures Congress, May 8-10. Sponsored by ASCE/SEI, Philadelphia, Pennsylvania, USA

Krishna, P., 1995. Wind loads on low-rise buildings - a review. Journal of Wind Engineering and Industrial Aerodynamics 54-55, 383-396

NBC2010, 2010. User's Guide - NBC 2010, Structural Commentaries (part 4), Issued by the Canadian Commission on Buildings and Fire Codes, National Research Council of Canada EN 1991-1-4, 2005. Eurocode 1, 2005: Actions on Structures - General actions - Part 1-4: Wind actions, European Standard

Stathopoulos, T., 1984. Wind Loads on Low-rise Buildings - A Review of the State of the Art, Engineering Structures 6, 119-135 


\section{List of figures captions}

Figure 1. American Association of Wind Engineering web site (http://www.aawe.org/gallery/? $p=3 \& c=$ ), low building damage possibly caused by windinduced torsion

Figure 2. Schematic representation of load configurations used to evaluate wind-induced torsion

Figure 3. Simplified method - load case: maximum torsion and corresponding shear force

Figure 4. Detailed method - load case: maximum torsion and corresponding shear force

Figure 5. Comparison of the torsional load cases specified for medium height buildings in ASCE 7-10, NBCC 2010, and EN 1991-1-4

Figure 6. Peak torsional coefficients for three low buildings evaluated by the three codes/standards and compared with wind tunnel results

Figure 7. Wind tunnel models: A) Building with a flat roof, B) Building with $18.4^{\circ}$ roof angle, C) Building with $45^{\circ}$ roof angle, D) Heights tested

Figure 8. Wind tunnel velocity and turbulence intensity profiles for open and urban exposures

Figure 9. Instantaneous wind pressure distributions, generated wind forces $\left(\mathrm{F}_{\mathrm{X}}, \mathrm{F}_{\mathrm{Y}}\right)$ and torsional moment $\left(\mathrm{M}_{\mathrm{T}}\right)$

Figure 10. Shear coefficients in $\mathrm{X}, \mathrm{Y}$ and total for each building model in open terrain exposure

Figure 11. Torsional coefficients for the three buildings (A, B, and C) tested at full eave heights in open and urban terrain exposure

Figure 12. Maximum shear and torsional coefficients, evaluated by different codes/standards and wind tunnel tests, for Buildings $\mathrm{A}, \mathrm{B}$, and $\mathrm{C}$ in open terrain exposure 
Figure 1. American Association of Wind Engineering web site (http://www.aawe.org/gallery/?p=3\&c=), low building damage possibly caused by windinduced torsion

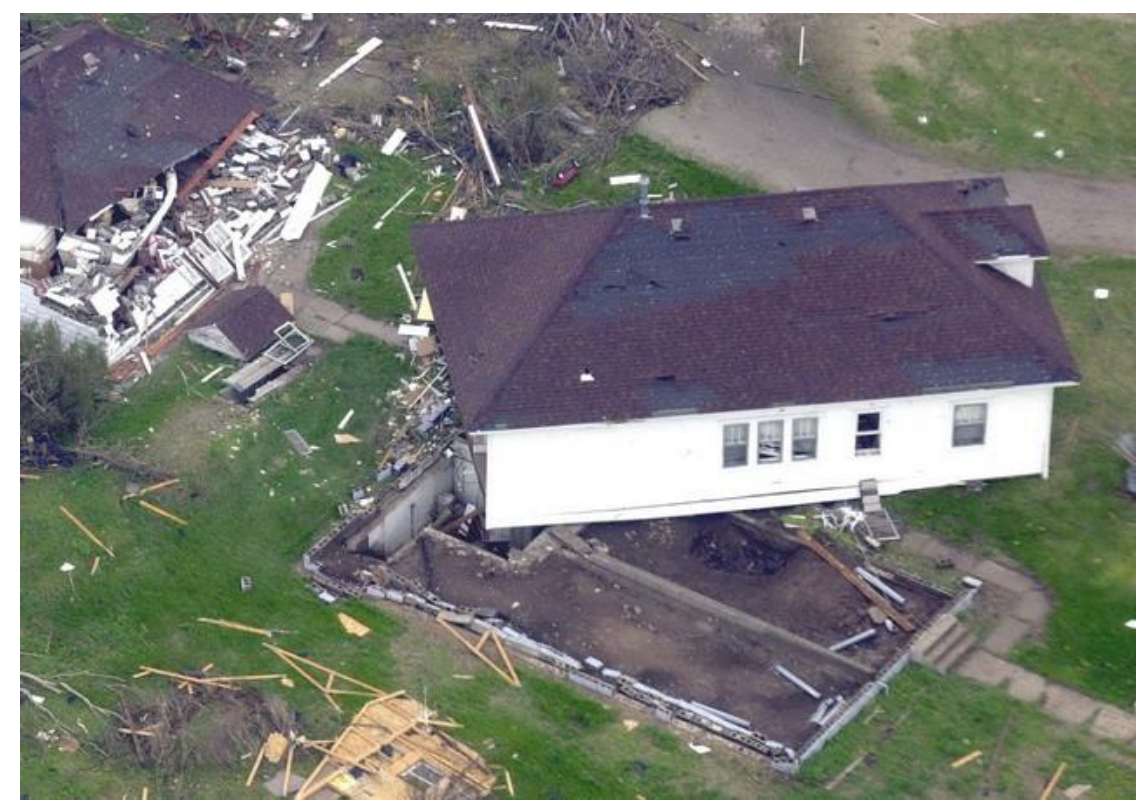


Figure 2. Schematic representation of load configurations used to evaluate wind-induced torsion

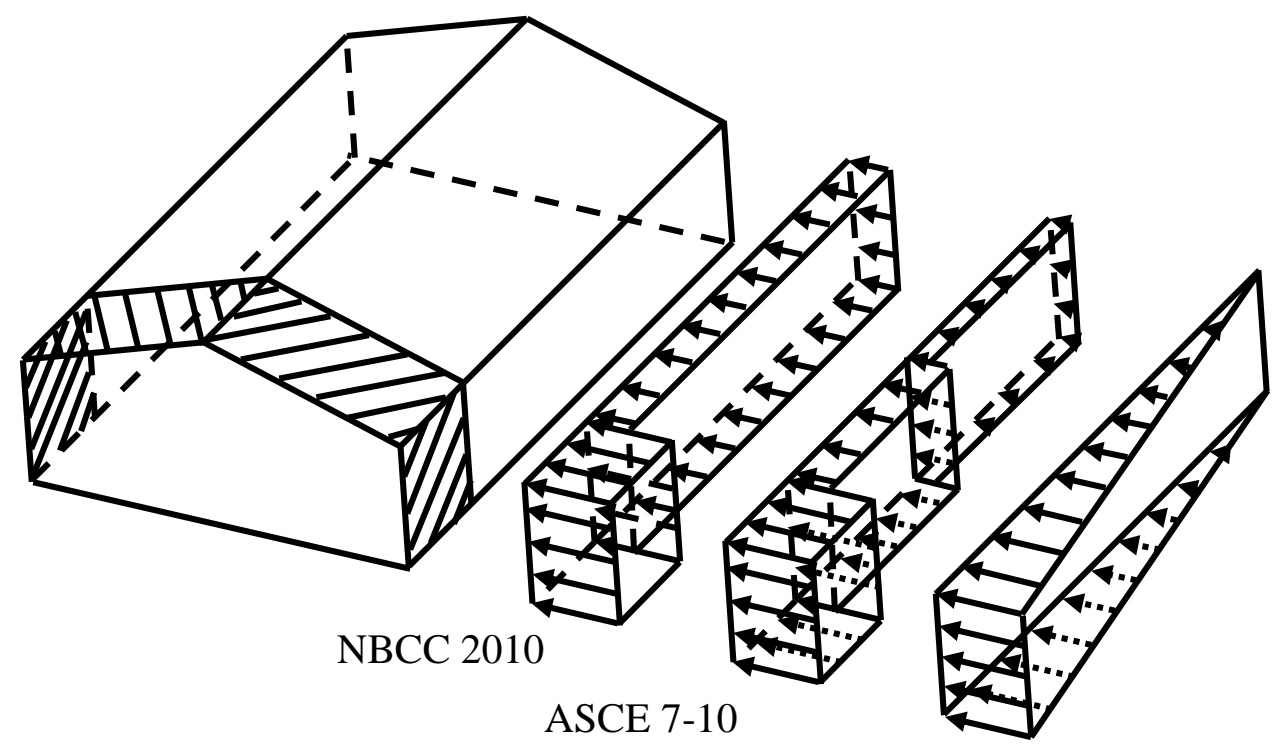

EN 1991-1-4 
Figure 3. Simplified method - load case: maximum torsion and corresponding shear force




Figure 4. Detailed method - load case: maximum torsion and corresponding shear force

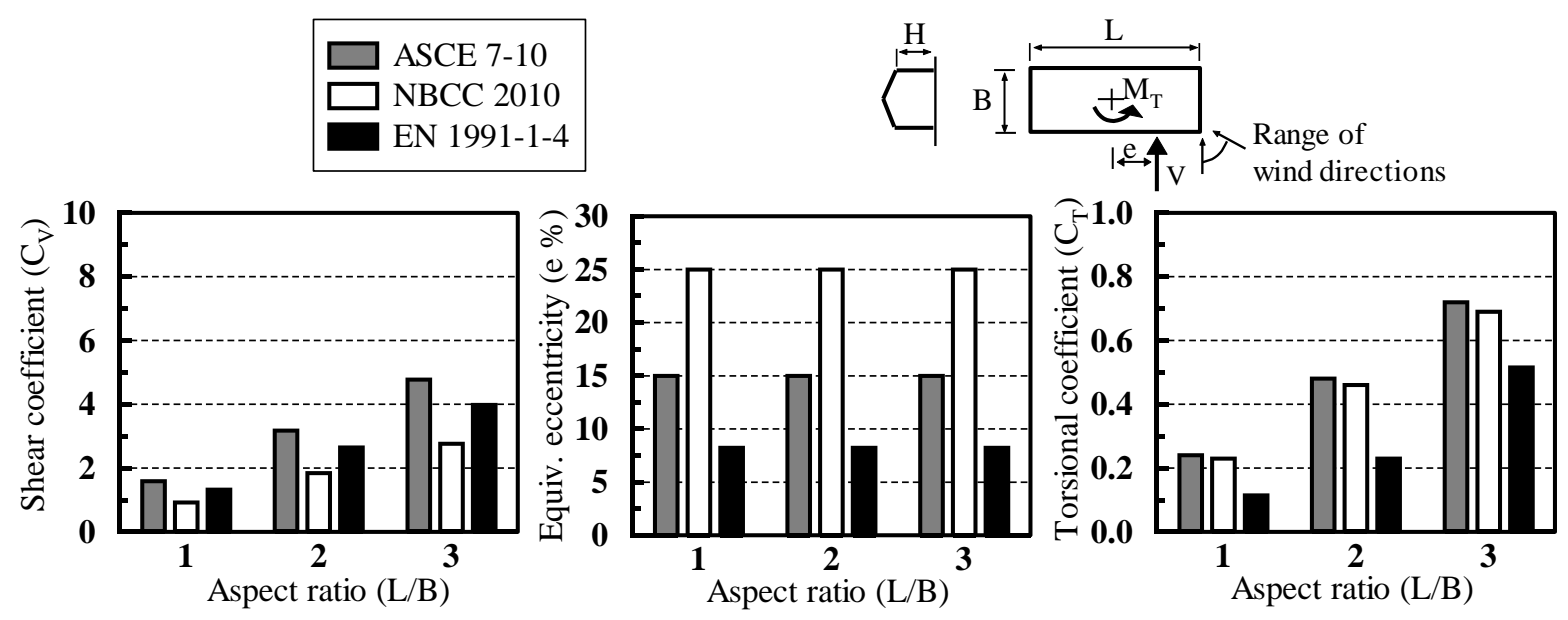


Figure 5. Comparison of the torsional load cases specified for medium height buildings in ASCE 7-10, NBCC 2010, and EN 1991-1-4

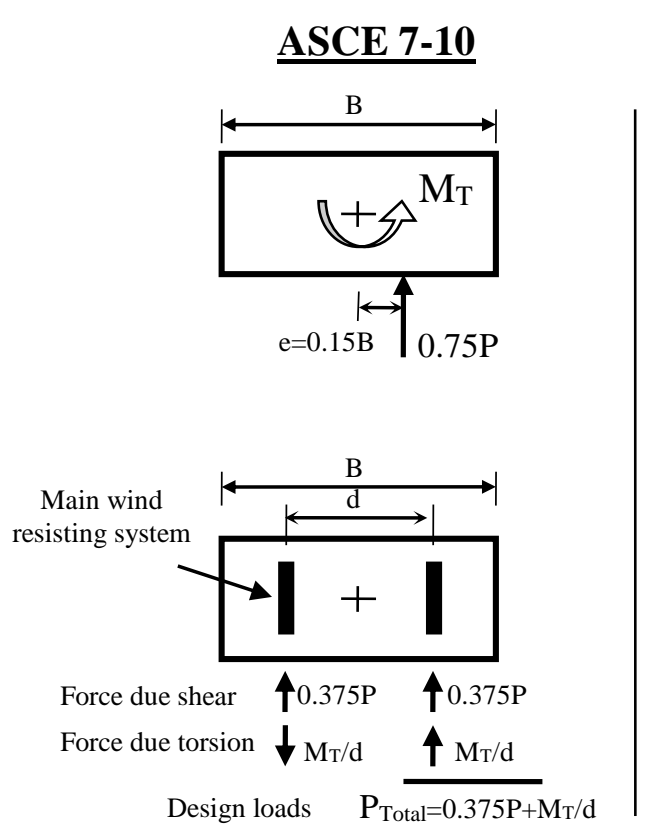

\section{NBCC 2010}
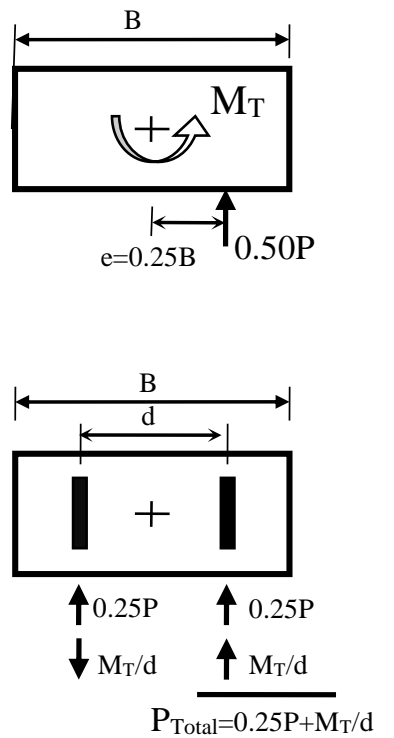

\section{EN 1991-1-4}
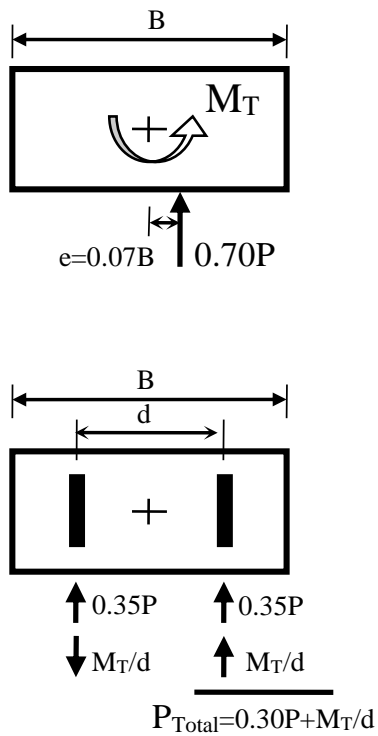
Figure 6. Peak torsional coefficients for three low buildings evaluated by the three codes/standards and compared with wind tunnel results

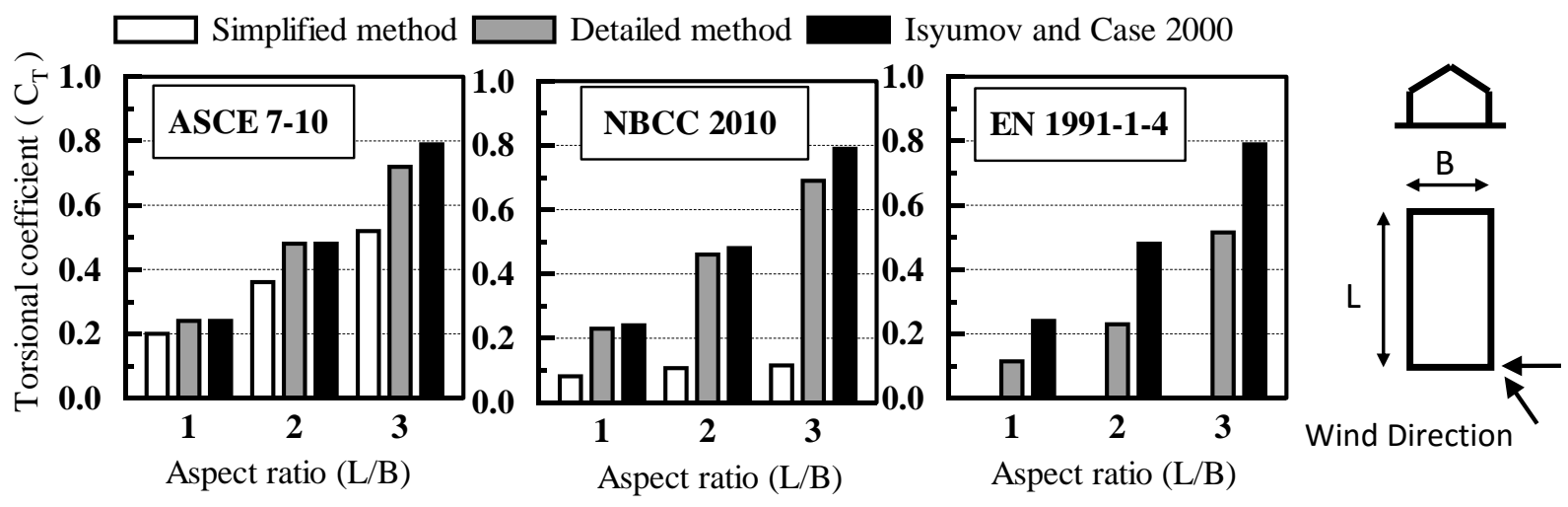


Figure 7. Wind tunnel models: A) Building with a flat roof, B) Building with $18.4^{\circ}$ roof angle, C) Building with $45^{\circ}$ roof angle, D) Heights tested

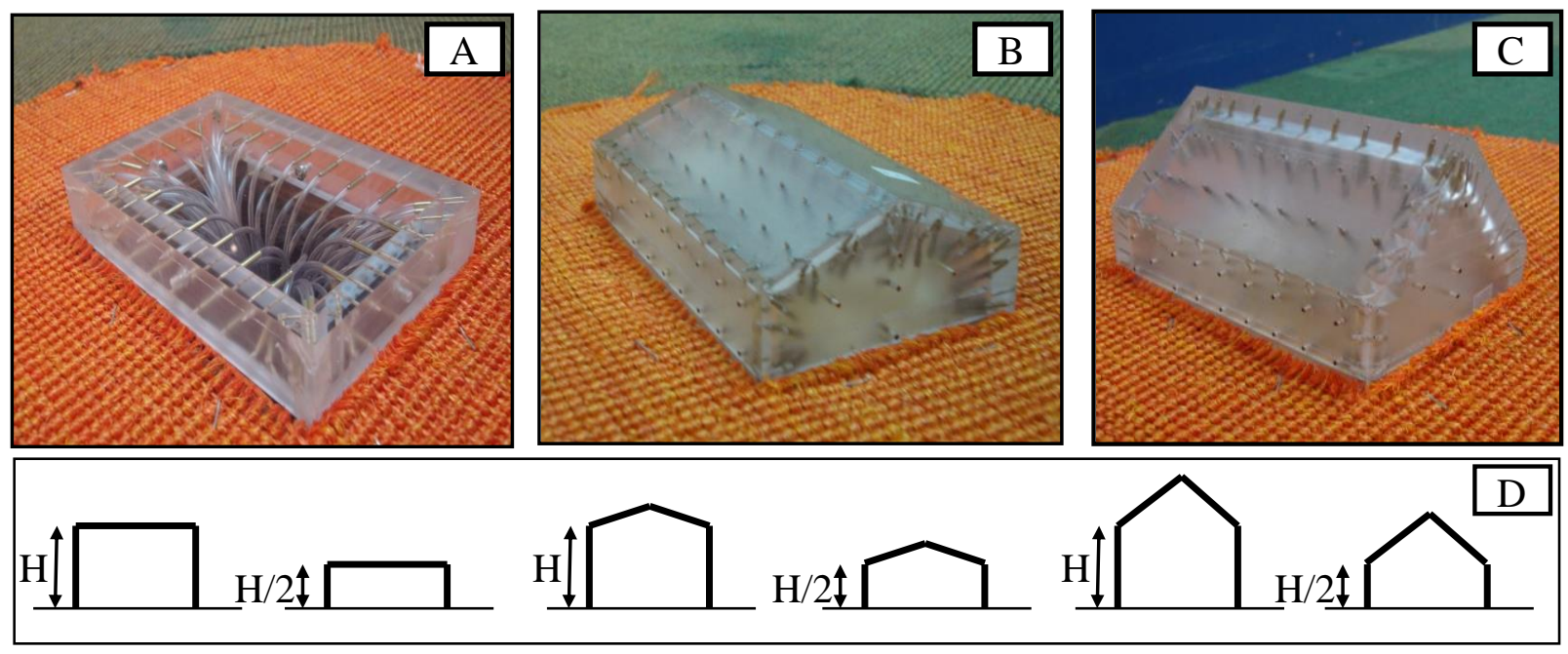


Figure 8. Wind tunnel velocity and turbulence intensity profiles for open and urban exposures

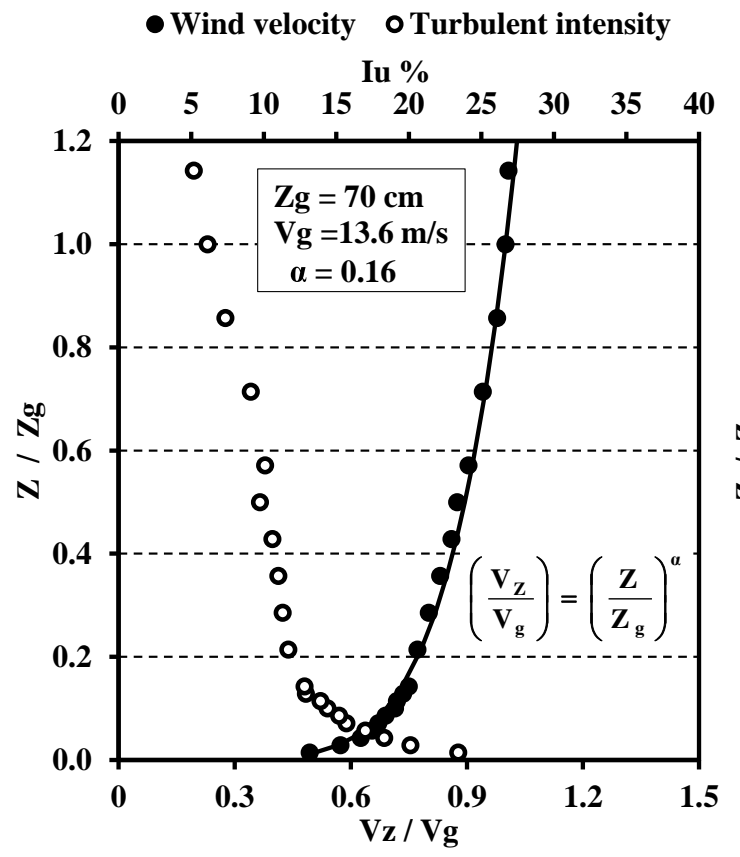

- Wind velocity o Turbulent intensity

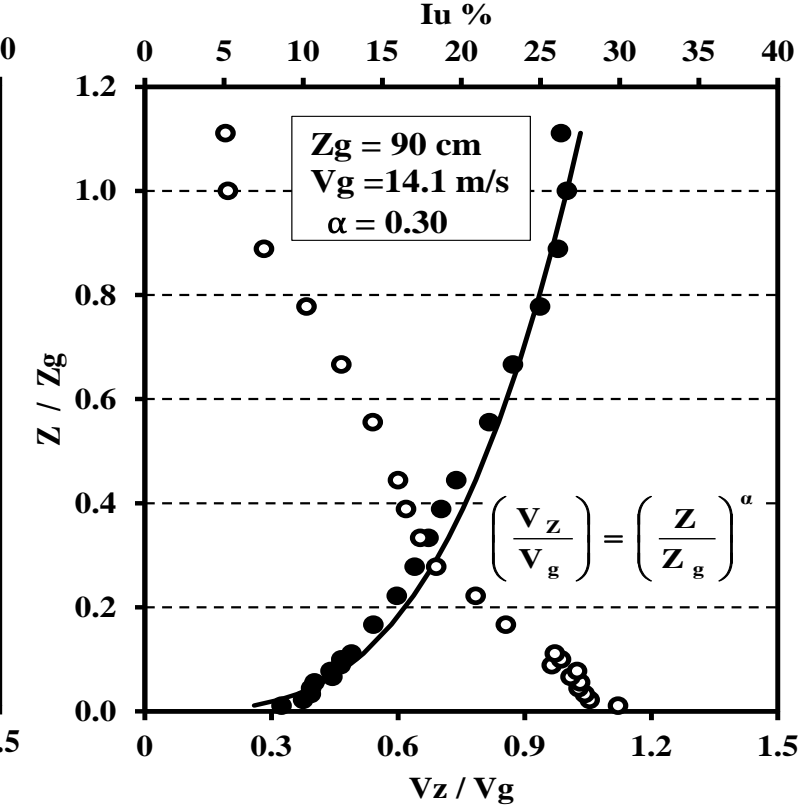


Figure 9. Instantaneous wind pressure distributions, generated wind forces $\left(F_{X}, F_{Y}\right)$ and torsional moment $\left(\mathrm{M}_{\mathrm{T}}\right)$

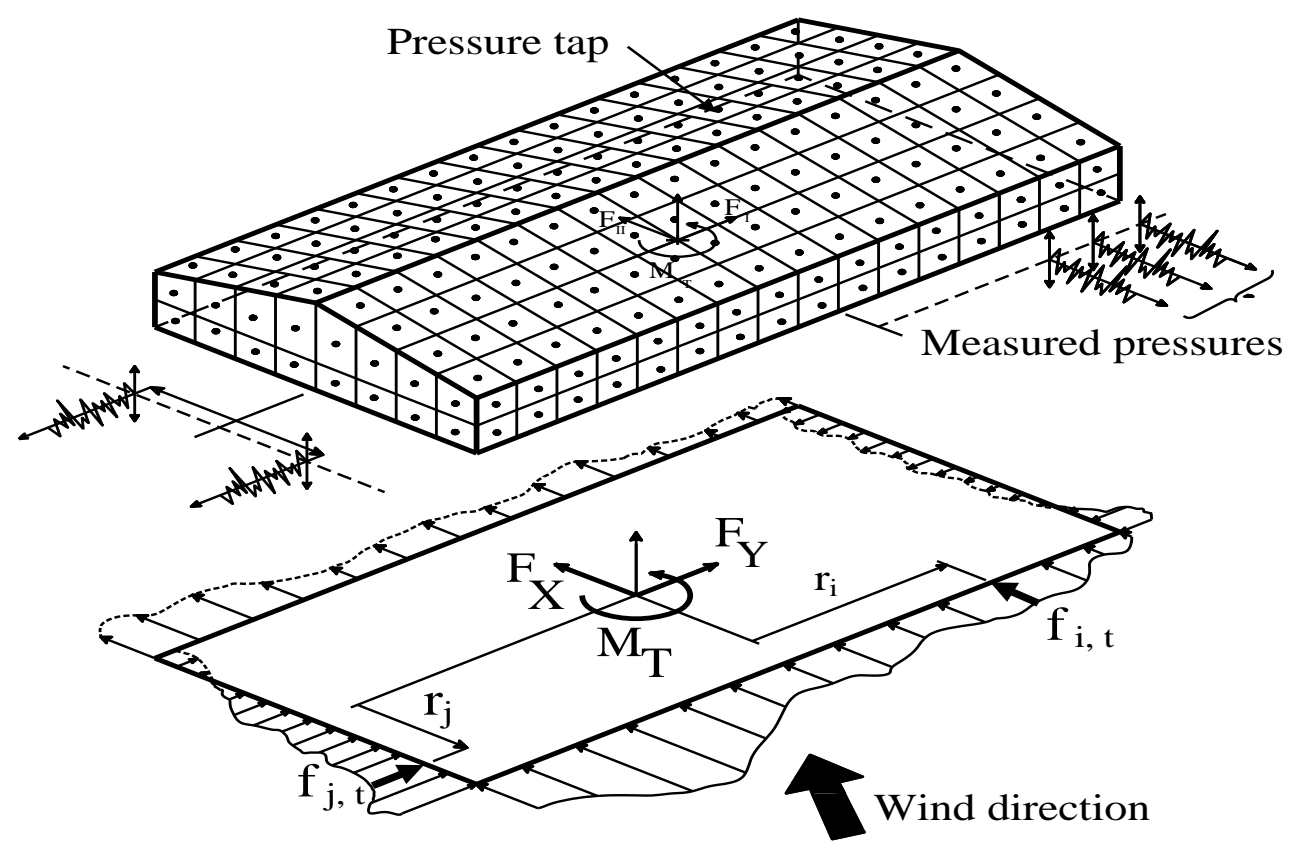


Figure 10. Shear coefficients in $\mathrm{X}, \mathrm{Y}$ and total for each building model in open terrain exposure

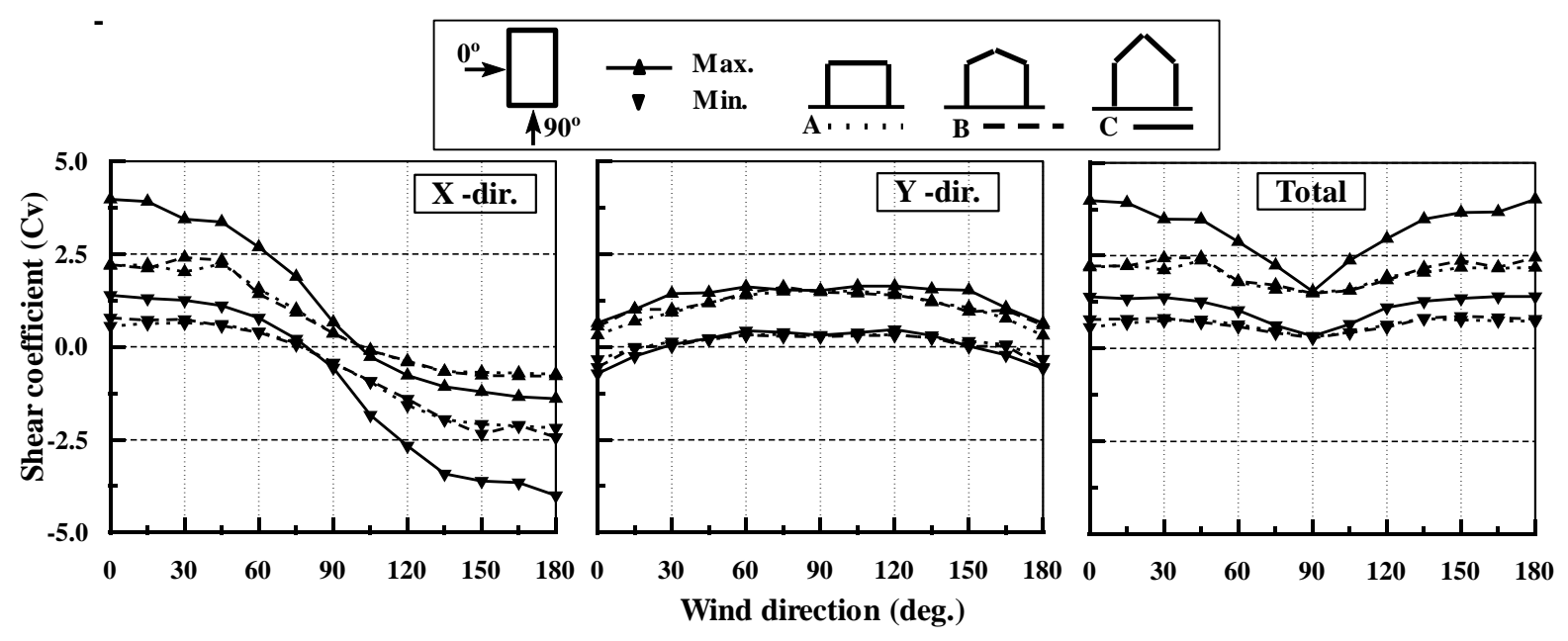


Figure 11. Torsional coefficients for the three buildings (A, B, and C) tested at full eave heights in open and urban terrain exposure
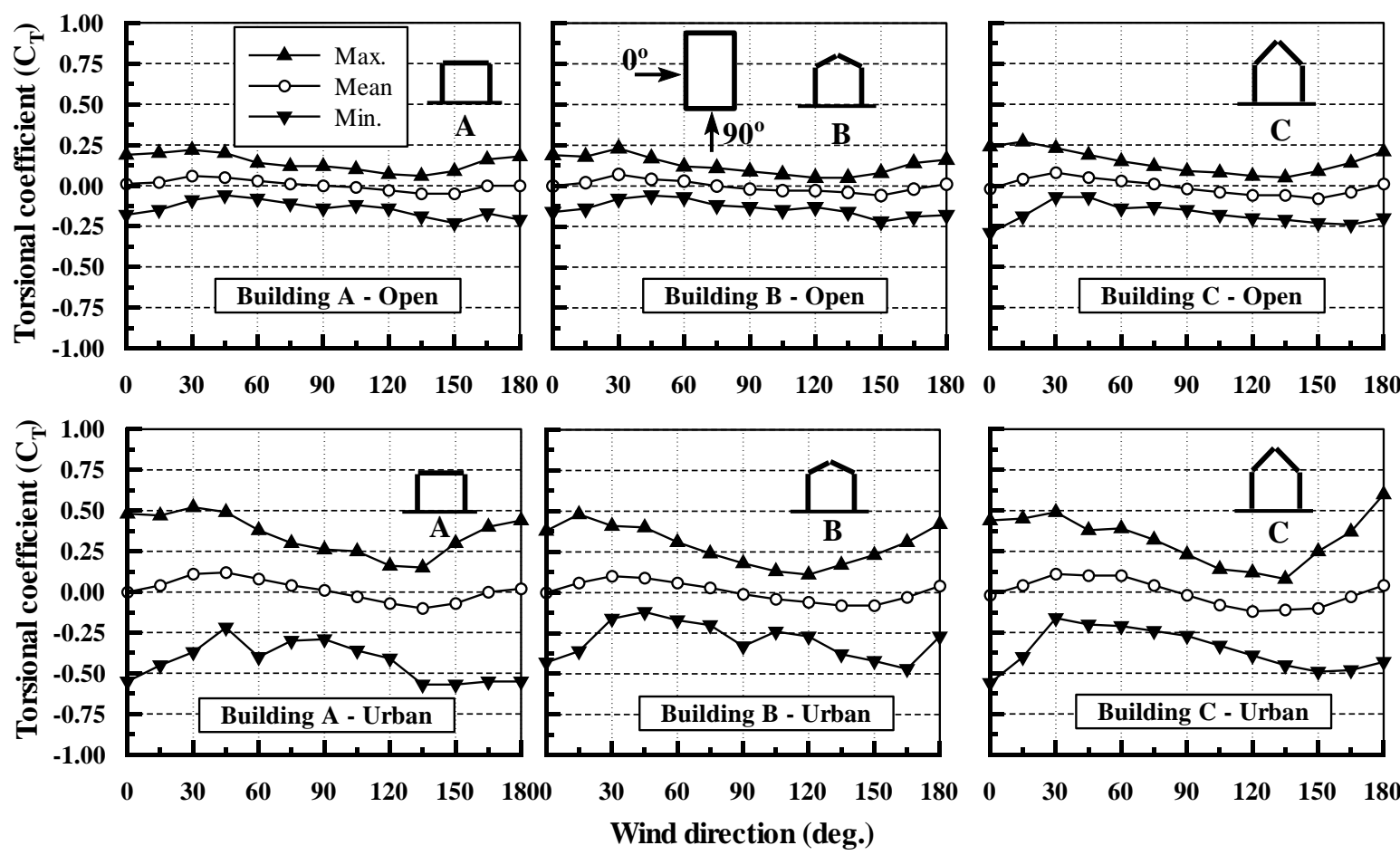
Figure 12. Maximum shear and torsional coefficients, evaluated by different codes/standards and wind tunnel tests, for Buildings $\mathrm{A}, \mathrm{B}$, and $\mathrm{C}$ in open terrain exposure
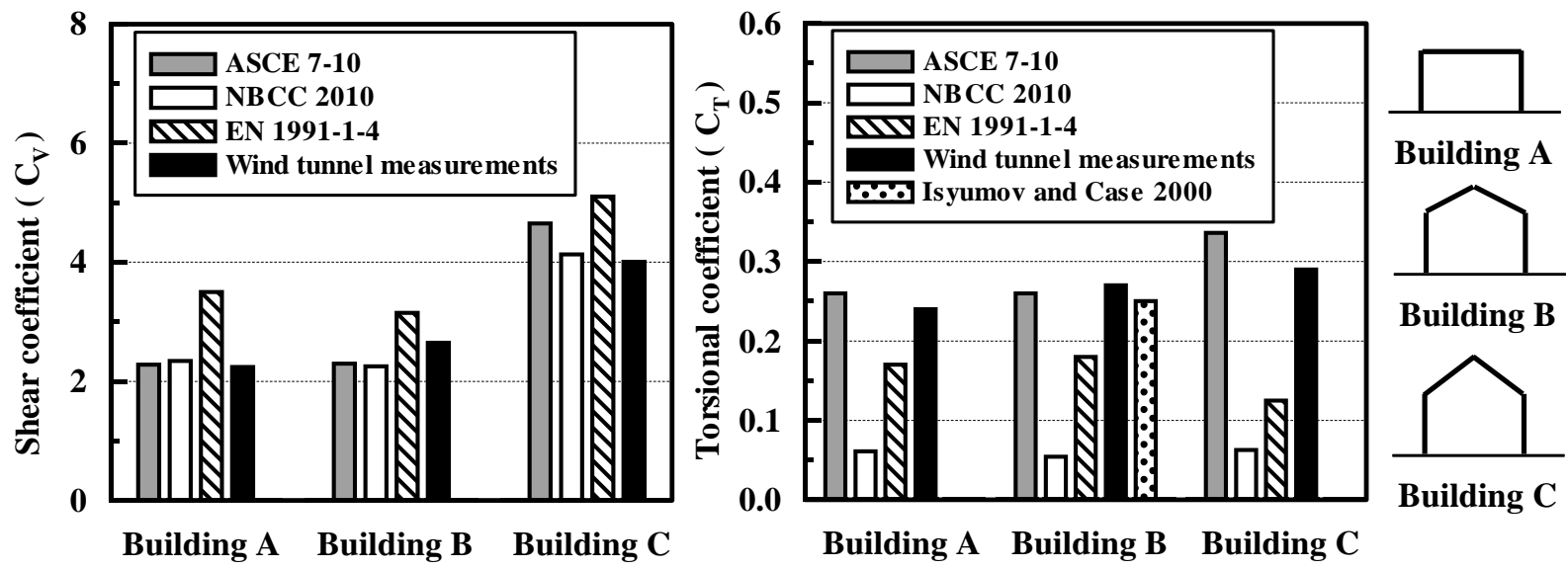


\section{List of Tables captions}

Table (1): Most critical values for shear coefficients (open and urban terrain exposures)

Table (2): Most critical values for torsional coefficients (open and urban terrain exposures) 
Table (1): Most critical values for shear coefficients (open and urban terrain exposures)

\begin{tabular}{|c|c|c|c|c|c|c|c|c|c|c|c|}
\hline & & & \multicolumn{3}{|c|}{ Building A $\left(0^{\circ}\right)$} & \multicolumn{3}{|c|}{ Building B (18.4 $\left.{ }^{\circ}\right)$} & \multicolumn{3}{|c|}{ Building C (45 $)$} \\
\hline & & & $X$-dir. & $Y$-dir. & Total & $X$-dir. & $Y$-dir. & Total & $X$-dir. & $Y$-dir. & Total \\
\hline \multirow{4}{*}{$\begin{array}{c}\text { Shear } \\
\text { Coefficient } \\
\left(\mathbf{C}_{v \text { Max }}\right)\end{array}$} & \multirow{2}{*}{$\begin{array}{l}\text { Open } \\
\text { terrain }\end{array}$} & Full height & 2.24 & 1.52 & 2.37 & 2.44 & 1.60 & 2.45 & 4.00 & 1.65 & 4.01 \\
\hline & & Half height & 2.15 & 1.40 & 2.15 & 2.55 & 1.35 & 2.61 & 4.45 & 1.65 & 4.46 \\
\hline & \multirow{2}{*}{$\begin{array}{l}\text { Urban } \\
\text { terrain }\end{array}$} & Full height & 5.90 & 3.53 & 5.53 & 5.02 & 3.22 & 5.08 & 8.24 & 3.00 & 8.26 \\
\hline & & Half height & 6.56 & 4.15 & 6.61 & 6.80 & 3.60 & 7.00 & 9.36 & 3.33 & 9.50 \\
\hline
\end{tabular}


Table (2): Most critical values for torsional coefficients (open and urban terrain exposures)

\begin{tabular}{|c|c|c|c|c|c|}
\hline & & & Building A $\left(0^{\circ}\right)$ & Building B $\left(18.4^{\circ}\right)$ & Building $C\left(\mathbf{4 5}^{\circ}\right)$ \\
\hline \multirow{4}{*}{$\begin{array}{c}\text { Torsional } \\
\text { Coefficient } \\
\left(\mathbf{C}_{T \text { Max }}\right)\end{array}$} & \multirow{2}{*}{$\begin{array}{l}\text { Open } \\
\text { terrain }\end{array}$} & Full height & 0.23 & 0.23 & 0.29 \\
\hline & & Half height & 0.20 & 0.23 & 0.31 \\
\hline & \multirow{2}{*}{$\begin{array}{c}\text { Urban } \\
\text { terrain }\end{array}$} & Full height & 0.57 & 0.48 & 0.60 \\
\hline & & Half height & 0.66 & 0.60 & 0.78 \\
\hline
\end{tabular}

